\title{
Desenvolvimento de Girinos de Rã-Touro (Rana catesbeiana, Shaw, 1802) Cultivados em Diferentes Densidades de Estocagem em Tanques-rede
}

\author{
Carmino Hayashi $^{*}$, Claudemir Martins Soares ${ }^{2}$, Eliana Maria Galdioli², Valéria Rossetto \\ Barriviera Furuya ${ }^{3}$, Wilson Rogério Boscolo ${ }^{4}$
}

\begin{abstract}
RESUMO - Objetivou-se, nesta pesquisa, avaliar o efeito da densidade de estocagem sobre o desenvolvimento de girinos de rã-touro em tanques-rede. Foram utilizados 360 girinos com peso médio inicial 0,01g e comprimento inicial médio de 0,92 $\pm 0,06 \mathrm{~cm}$, distribuídos em um delineamento em blocos ao acaso com cinco tratamentos $(0,50 ; 1,00 ; 1,50 ; 2,00$ e 2,50 indivíduos/L) e quatro repetições, em 20 tanques-rede experimentais (12 L). Foi fornecida dieta com 40,00\% de proteína bruta, na proporção de $8,00 \%$ do peso vivo, duas vezes ao dia. Observou-se aumento linear da biomassa por tanque, em função da densidade de estocagem. O peso final médio e a taxa de sobrevivência apresentaram redução linear, com o aumento da densidade. Observaram-se lotes mais uniformes dos girinos cultivados em menores densidades. A conversão alimentar não foi influenciada pelas diferentes densidades de estocagem. As variáveis físico-químicas da água estiveram em níveis adequados. Concluiu-se que, com menores densidades, obtêm-se girinos maiores e lotes mais uniformes com melhor taxa de sobrevivência.
\end{abstract}

Palavras-chave: densidade de estocagem, girinos, Rana catesbeiana, ranicultura, rã-touro, tanques-rede

\section{Development of Bullfrog (Rana Catesbeiana, Shaw, 1802) Tadpoles Reared at Different Stocking Densities in Net Tanks}

\begin{abstract}
This research was conducted to evaluate the effect of different stocking density on the bull-frogs tadpoles development in net-pond. Three hundred and sixty animals, averaging initial weight of $0.01 \mathrm{~g}$ and initial length of $.92 \pm .06 \mathrm{~cm}$ were allotted to $20 \mathrm{net}-$ pond (12L) in a block randomized design with five treatments $(.5,1.0,1.5,2.0$ and 2.5 tadpoles/L) and four replicates. The diet with $40.00 \%$ crude protein was fed twice a day at $8.00 \%$ live weight. Linear increase in biomass, as the stocking rates increased, was observed. Average final weight and the survival rate showed linear decrease, as the stocking rates increased. It was observed more uniformity groups in the lower density. Feed/gain was not affected by the different stocking rates. Physical and chemical traits had adequate levels. It was concluded that, under low stocking rates, better results of weight, uniformity of group and survival rate of the tadpoles were obtained.
\end{abstract}

Key Words: bullfrog, stocking density, Rana catesbeiana, raniculture, tadpoles, net-ponds

\section{Introdução}

A ranicultura tem se tornado uma importante atividade econômica em muitos países (RodríguezSerna et al., 1996). No Brasil, esta atividade teve início em 1935, com a importação da rã-touro (Rana catesbeiana), a qual se adaptou bem às condições climáticas deste país (Vizotto, 1984), sendo atualmente a espécie mais utilizada nos criatórios brasileiros (Lima et al., 2000). O consumo de rãs tem aumentado a cada ano, sendo necessária a determinação de técnicas de manejo para o cultivo destes animais, seja para o consumo humano ou para a produção de animais a serem utilizados em educação biomédica, ensino e pesquisas (Martinéz et al., 1996). Alguns fatores que limitam o desenvolvimento da ranicultura brasileira relacionam-se à falta de conhecimento específico sobre a determinação de técnicas de manejo, durante a fase de desenvolvimento dos girinos, visando à produção de imagos, como por exemplo a determinação da densidade adequada de estocagem. Na ranicultura, a fase de criação de girinos é de grande importância, pois determina a produção de imagos de qualidade, em quantidade para a fase de engorda (Castro \& Pinto, 2000; Soares et al., 2001), com índices zootécnicos satisfatórios (Seixas Filho et al., 1998; Soares et al., 2001). A mortalidade de girinos e imagos pode constituir um

1 Professor Titular do Departamento de Biologia/Universidade Estadual de Maringá. E.mail: chayashi@netsite.com.br

2 Biólogo, Dr., do Departamento de Biologia/Universidade Estadual de Maringá

3 Zootecnista, Doutora em Ciências pela Universidade Estadual de Maringá.

4 Zootecnista, Dr., Professor Assistente do curso de Engenharia de Pesca/UNIOESTE - Toledo, PR. E.mail: wrboscolo@unioeste.br

* Av. Colombo 5790, Jardim Universitário, Maringá PR, Brasil. CEP: 97020-900. 
ponto de estrangulamento na ranicultura (Castro \& Pinto, 2000). Dessa forma, a determinação de instalações apropriadas e técnicas de manejo adequadas para esta fase é de fundamental importância para o desenvolvimento desta atividade.

Entre os fatores que afetam o desenvolvimento de girinos estão densidade, temperatura, qualidade de água, fotoperíodo, características físicas e químicas e teor protéico da dieta (Soares et al., 1983; Justo et al., 1985; Carmona-Osalde et al., 1996; Figueiredo et al., 1999; Castro \& Pinto, 2000; Soares et al., 2001). Por outro lado, características inerentes à autoecologia de cada espécie, como competição por espaço e alimento, hierarquia e produção de um fator inibidor de crescimento, são também indicados como mecanismos que determinam o desenvolvimento de girinos de rãs do gênero Rana (Martinéz et al., 1996; Browne et al., 2002).

A densidade de estocagem durante o cultivo de girinos é um dos mais importantes fatores para a criação de anuros (Martinéz et al., 1996), sendo um dos parâmetros mais importantes para o aproveitamento máximo da potencialidade econômica do cultivo dessa espécie.

$\mathrm{O}$ aumento na densidade de estocagem promove redução no peso médio dos imagos obtidos, aumento no tempo de metamorfose, incremento da taxa de mortalidade e aumento na variação de tamanho dos lotes, devido a mudanças na qualidade da água e competição por alimento (Martinéz et al., 1996; Newman, 1998; Castro e Pinto, 2000; Browne et al., 2002; Gillespie, 2002). Em tanques individualizados, como os escavados ou os tanques de concreto, o efeito do aumento da densidade de estocagem sobre o desempenho dos girinos de rã touro é normalmente atribuído, principalmente, à piora na qualidade da água.

A densidade de estocagem adequada a ser utilizada na criação de girinos de rã-touro, mesmo em tanques convencionais, ainda não esta bem definida. Adams \& Bruinsma (1987) indicam a densidade de 1 a 2 girinos/L, enquanto Albinati et al. (1998) sugerem o uso de 0,10 girinos/L para o cultivo de girinos de rãtouro, em condições práticas. Portanto, a determinação de uma densidade adequada, visando à obtenção de imagos de qualidade (tamanho adequado e com desempenho satisfatório) e em quantidade para posterior utilização na fase de recria é de extrema necessidade. Os objetivos deste trabalho foram avaliar o efeito da densidade de estocagem sobre o desenvolvimento de girinos de rã-touro em tanque- rede e determinar a densidade de estocagem adequada para criação de girinos neste sistema.

\section{Material e Métodos}

O experimento foi realizado no Laboratório de Aqüicultura do Departamento de Biologia da Universidade Estadual de Maringá - PR, no período de 29 de setembro à 05 de dezembro de 1999. Foram utilizados 360 girinos com peso inicial médio $0,01 \mathrm{~g}$ e comprimento inicial médio de $0,92 \pm 0,06 \mathrm{~cm}$, com 72 horas de vida, obtidos por reprodução natural.

O delineamento experimental utilizado foi o de blocos ao acaso, com cinco tratamentos, os quais diferiam quanto à densidade de estocagem dos girinos sendo utilizados 0,$50 ; 1,00 ; 1,50 ; 2,00$ e 2,50 ind./L, com quatro repetições. Foram utilizados 20 tanquesrede experimentais com capacidade para $12 \mathrm{~L}$, distribuídos em duas caixas de fibrocimento com capacidade para $1000 \mathrm{~L}$. Os tratamentos foram distribuidos mediante sorteio, tomando-se o cuidado para que duas repetições de cada tratamento ficassem em cada caixa de fibrocimento, sendo, então, cada caixa considerada como um bloco.

Os tanques possuíam aeração com uma pedra porosa por unidade experimental, sendo também mantida uma taxa de circulação de $10,0 \%$ do volume total da água por dia. A entrada de água era realizada próxima à borda da caixa e à tomada do sifão de saída instalado na parede oposta à da entrada de água, a 10 $\mathrm{cm}$ do fundo da caixa.

Para confecção da ração, os ingredientes foram processadps em moinho tipo faca com peneira de $0,50 \mathrm{~mm}$ de diâmetro de abertura e misturados, sendo a ração formulada com $40,00 \%$ de proteína bruta (Tabela 1). A dieta foi fornecida na proporção de $8,0 \%$ do peso vivo, duas vezes ao dia, sendo a quantidade corrigida mediante pesagem de todos os indivíduos a cada sete dias.

Diariamente, os fundos dos tanques-rede foram sifonados para retirada das fezes acumuladas, enquanto os fundos das caixas de fibrocimento foram sifonados semanalmente para retirada do sedimento.

As variáveis físico-químicas da água foram monitoradas no período experimental, sendo a temperatura tomada pela manhã $(8 \mathrm{~h})$ e à tarde $(17 \mathrm{~h})$, enquanto o $\mathrm{pH}$, a condutividade elétrica e o oxigênio dissolvido foram medidos semanalmente.

Ao final do período experimental, os animais de cada unidade experimental foram contados, pesados 
e medidos individualmente. Para avaliar a uniformidade dos lotes dos girinos em cada tanque-rede, realizou-se a adaptação de uma equação descrita por Furuya et al. (1998), a qual foi proposta para determinar a uniformidade em peso de peixes. Com base nos dados coletados, calculou-se a média de peso dos girinos para cada unidade experimental. Foram quantificados o número de indivíduos com tamanho dentro do intervalo correspondente a $10 \%$ acima e abaixo do peso médio de cada unidade experimental.

A equação utilizada para o calculo da uniformidade do lote dos girinos foi:

$$
U=\frac{N_{t}}{N_{ \pm 10 \%}} \times 100
$$

em que $\mathrm{U}=$ uniformidade do lote: percentagem de animais $10 \%$ acima ou abaixo do peso médio; $\mathrm{N}_{\mathrm{t}}=$ numero total de girinos no tanque rede; $\mathrm{N}_{ \pm 10}=\mathrm{n} \underline{\mathrm{o}}$ de animais com peso total entre $10 \%$ acima ou abaixo do peso médio do tanque.

Os dados obtidos foram submetidos à análise de variância, a 5\% de significância. Em caso de diferenças significativas, ajustou-se uma equação de regres- são polinomial. O programa Sistema de Análises Estatísticas e Genética (Euclydes, 1983) foi utilizado para realizar as análises estatísticas.

O modelo de regressão utilizado para as análises das variáveis estudadas foi:

$$
Y_{i j k}=\mu+B_{i}+b_{1}\left(D_{j}-D\right)+b_{2}\left(D_{j}-D\right)^{2}+e_{i j k}
$$

em que: $Y_{\mathrm{ijk}}=$ observação referente ao tanque-rede $\mathrm{k}$ instalado no bloco $\mathrm{i}$, onde se utilizou a densidade de estocagem $\mathrm{j} ; \mathrm{m}=$ constante geral; $\mathrm{B}_{\mathrm{i}}=$ efeito do bloco $\mathrm{i} ; \mathrm{b}_{1}=$ coeficiente de primeiro grau de regressão da variável $\mathrm{Y}$, em função da densidade de estocagem j; $\mathrm{b}_{2}=$ coeficiente quadrático de regressão da variável Y, em função da densidade de estocagem $\mathrm{j} ; \mathrm{D}_{\mathrm{j}}=$ nível $\mathrm{j}$ de densidade de estocagem; $\mathrm{D}=$ média das densidade de estocagem utilizadas; $\mathrm{e}_{\mathrm{ijk}}=$ desvio aleatório associado a cada observação $\mathrm{Y}_{\mathrm{ij}}$.

\section{Resultados e Discussão}

Os valores médios dos parâmetros físico-químicos da água durante o período experimental encontram-se na Tabela 2. Estes permaneceram nos níveis adequados para a aquicultura, segundo Egna \& Boyd

\begin{tabular}{|c|c|c|c|}
\hline \multicolumn{2}{|l|}{$\begin{array}{l}\text { Alimentos }(\%) \\
\text { Feeds }\end{array}$} & \multicolumn{2}{|l|}{$\begin{array}{l}\text { Nutrientes } \\
\text { Nutrients }\end{array}$} \\
\hline Farinha de peixe & 21,50 & Energia digestível (kcal/kg) ${ }^{2}$ & 3105,80 \\
\hline Fish meal & & Digestible energy & \\
\hline Farelo de soja & 42,24 & Cálcio $(\%)$ & 3,44 \\
\hline Soybean meal & & Calcium & \\
\hline Farinha de carne & 15,00 & Fósforo total (\%) & 1,87 \\
\hline Meat meal & & Total phosphorus & \\
\hline Milho & 20,64 & Fibra bruta $(\%)$ & 3,57 \\
\hline Corn & & Crude fiber & \\
\hline Premix mineral vitamínico ${ }^{1}$ & 0,60 & Metionina + cistina $(\%)$ & 1,50 \\
\hline Mineral and vitamin mix & & Methionine + Cystine & \\
\hline \multirow[t]{6}{*}{ BHT } & 0,02 & $\operatorname{Lisina}(\%)$ & 1,80 \\
\hline & & Lysine & \\
\hline & & Proteína bruta (\%) & 40,00 \\
\hline & & Crude protein & \\
\hline & & Proteína digestível $(\%)^{2}$ & 36,80 \\
\hline & & Digestible protein & \\
\hline
\end{tabular}
(1997).

\footnotetext{
${ }^{1}$ Níveis de garantia por quilograma do produto (Guarantee levels by product kilogram): Vit. A, 1.200.000UI; Vit. $D_{3}, 200.000$ Ul; Vit. E, 12.000 mg; Vit. K3, 2.400 mg; Vit. B1, 4.800 mg; Vit. B2, 4.800 mg; Vit. B6, 4.000 mg; Vit. B12, 4.800 mg; Ác. Fólico, 1.200 mg; Pantotenato Ca, 12.000 mg; Vit. C, 48.000 mg; Biotina, $48 \mathrm{mg}$; Colina, 65.000mg; Niacina, 24.000mg; Ferro (iron), $10.000 \mathrm{mg}$; Cobre, $6.000 \mathrm{mg}$; Manganês, $4.000 \mathrm{mg}$; Zinco, $6.000 \mathrm{mg}$; lodo, $20 \mathrm{mg}$; Cobalto, $2 \mathrm{mg}$; Selênio, $20 \mathrm{mg}$.

${ }^{2}$ Baseados nos valores propostos por Albinati et al. (2000).

${ }^{2}$ Based on the values proposed by Albinati et al. (2000).
} 
Na Tabela 3, estão apresentados os valores médios para peso inicial, biomassa final por tanque, peso final médio, conversão alimentar, taxa sobrevivência e uniformidade do lote de girinos de $R$. catesbeiana cultivados em tanques rede em diferentes densidades de estocagem durante 75 dias.

Observou-se aumento linear $(\mathrm{p}<0,05)$ da biomassa por tanque, em função da densidade de estocagem, enquanto o peso final médio e a taxa de sobrevivência

Tabela 2 - Valores médios dos parâmetros físicos e químicos durante o período experimental

Table 2 - Average values of physical and chemical parameters in the experimental period

\begin{tabular}{ll}
\hline Parâmetro & \\
Parameter & \\
\hline $\mathrm{pH}$ & $7,96 \pm 1,08$ \\
Oxigênio dissolvido $(\mathrm{mg} / \mathrm{L})$ & $9,98 \pm 1,94$ \\
$\begin{array}{l}\text { Dissolved oxygen } \\
\text { Condutividade elétrica }(\mathrm{mS} / \mathrm{cm})\end{array}$ & $0,13 \pm 0,02$ \\
Electric conductivity & \\
Temperatura - manhã $\left({ }^{\circ} \mathrm{C}\right)$ & $22,81 \pm 1,89$ \\
Temperature - morning & \\
Temperatura - tarde $\left({ }^{\circ} \mathrm{C}\right)$ & $25,72 \pm 2,29$ \\
Temperature - afternoon & \\
\hline
\end{tabular}

apresentaram redução linear $(\mathrm{p}<0,05)$, com o aumento da densidade (Figura 1). Entretanto, a conversão alimentar não foi influenciada pelas diferentes densidades de estocagem.

Estes resultados estão de acordo com o obtido por Soares et al. (1983) e Browne et al. (2002), que observaram redução nos valores de peso médio e sobrevivência de girinos da rã $R$. catesbeiana e Litoria aurea, respectivamente, em função do aumento na densidade de estocagem. Em outros trabalhos, como os de Justo et al. (1985), foi observada redução linear no ganho de peso utilizando densidades de $5,10,15$ e 20 ind/L de girinos de $R$. catesbeiana; Castro \& Pinto (2000), redução no desempenho de girinos de $R$. catesbeiana, com o aumento da densidade de estocagem $(0,50 ; 1,00 ; 1,50$ e 2,00 girinos/L), em tanques convencionais, e Gillespie (2002), redução no peso médio de girinos de Litoria spenceri mantidos em densidade de 3, 6 e 9 ind./L; resultados, portanto, semelhantes aos obtidos neste trabalho. Por outro lado, em relação à sobrevivência, os resultados discordam dos obtidos por Soares et al. (1983) com 1, 5,10 e 15 girinos/L de $R$. catesbeiana, em tanques de terra e por Hayashi et al. (2002) com girinos de Scinax fuscovaria, os quais relatam que a sobrevivência destes animais não foi influenciada pelo au-

Tabela 3 - Valores médios de os parâmetros de desempenho produtivo de girinos de rãtouro (Rana catesbeiana) cultivados sob diferentes densidades de estocagem em tanque-rede por 75 dias

Table 3 - Average values of the performance parameters of $R$. catesbeiana tadpoles at different stocking density in net tanks by 75 days

\begin{tabular}{|c|c|c|c|c|c|c|}
\hline \multirow{3}{*}{$\begin{array}{l}\text { Parâmetro } \\
\text { Parameter }\end{array}$} & \multirow{2}{*}{\multicolumn{5}{|c|}{$\begin{array}{c}\text { Densidade (Indivíduos/L) } \\
\text { Density }\end{array}$}} & \multirow{3}{*}{$\mathrm{CV}(\%)$} \\
\hline & & & & & & \\
\hline & 0,50 & 1,00 & 1,50 & 2,00 & 2,50 & \\
\hline Peso inicial médio (g) & 0,01 & 0,01 & 0,01 & 0,01 & 0,01 & 0,00 \\
\hline $\begin{array}{l}\text { Initial mean weight } \\
\text { Biomassa por tanque }(\mathrm{g})^{1}\end{array}$ & & & & & & \\
\hline $\begin{array}{l}\text { Biomassa por tanque }(\mathrm{g})^{1} \\
\text { Biomass by tank }\end{array}$ & 63,60 & 127,75 & 172,45 & 219,83 & 250,65 & 12,81 \\
\hline $\begin{array}{l}\text { Peso final médio }(\mathrm{g})^{2} \\
\text { Final mean weight }\end{array}$ & 11,08 & 10,43 & 10,00 & 9,77 & 9,82 & 5,49 \\
\hline $\begin{array}{l}\text { Conversão alimentar } \\
\text { Feed/gain }\end{array}$ & 1,04 & 1,02 & 0,91 & 0,86 & 0,93 & 16,20 \\
\hline $\begin{array}{l}\text { Sobrevivência }(\%)^{3} \\
\text { Survival rate }\end{array}$ & 100,00 & 95,83 & 93,06 & 93,75 & 85,00 & 9,56 \\
\hline $\begin{array}{l}\text { Survival rate } \\
\text { Uniformidade do lote }(\%)^{4^{*}} \\
\text { Group uniformity }\end{array}$ & 94,44 & 72,19 & 71,29 & 62,51 & 58,28 & 11,01 \\
\hline
\end{tabular}

\footnotetext{
${ }^{1}$ Efeito linear (linear effect) $(P<0,001)-Y=27,0025+93,2350 X \quad r^{2}=0,99$

2 Efeito linear (linear effect) $\quad(P<0,001)-Y=11,1721-0,0634117 X \quad r^{2}=0,85$

3 Efeito linear (linear effect) $\quad(P<0,001)-Y=103,153-0,641667 X \quad r^{2}=0,86$

${ }^{4}$ Efeito quadrático (quadratic effect) $(P<0,05)-Y=110,42400-4,05357 X+0,08045 X^{2}, r^{2}=0,93$

* Percentagem de animais $10 \%$ acima ou abaixo do peso médio.

* Percentage of animals $10 \%$ above or up the mean weight.
} 
mento da densidade de estocagem.

Em estudo com densidade de estocagem de girinos de perereca, Scinax fuscovaria $(0,67 ; 1,33 ; 1,67$ e 2,00 ind./L.), Hayashi et al. (2002) e Browne et al. (2002), trabalhando com L. aurea em densidade variando de 40 a 330 girinos /L, observaram aumento linear nos valores de biomassa dos girinos por aquário, resultados que estão de acordo com o obtido neste trabalho.

Os resultados obtidos para conversão alimentar diferem do obtido por Castro e Pinto (2000), que observaram melhores índices nas densidades mais baixas.

Os valores de uniformidade dos lotes dos girinos apresentaram comportamento quadrático, em função da densidade de estocagem. Os lotes mais uniformes foram obtidos com as menores densidades de estocagem (Figura 1). Estes resultados estão de acordo com Browne et al. (2002), os quais observaram que o aumento na densidade acarreta maior variação nos lotes de girinos. Relatos do efeito da densidade de estocagem sobre a uniformidade do lote de outros organismos aquáticos, como os peixes, foram feitos por Fontes et al. (1990), Dambo \& Rana (1992) e Khan (1994). De acordo com estes autores, o aumento na densidade promove maior variação de tamanho nos lotes dos animais, observações que concordam como obtido neste experimento. Este resultado deve estar relacionado com aspectos comportamentais, como competição por alimento e/ ou espaço, da espécie em estudo.

Redução dos valores de peso médio e sobrevivência e aumento na variação em peso dos lotes devem estar relacionados à autoecologia da espécie, como competição por alimento, e/ou fatores sociais, como
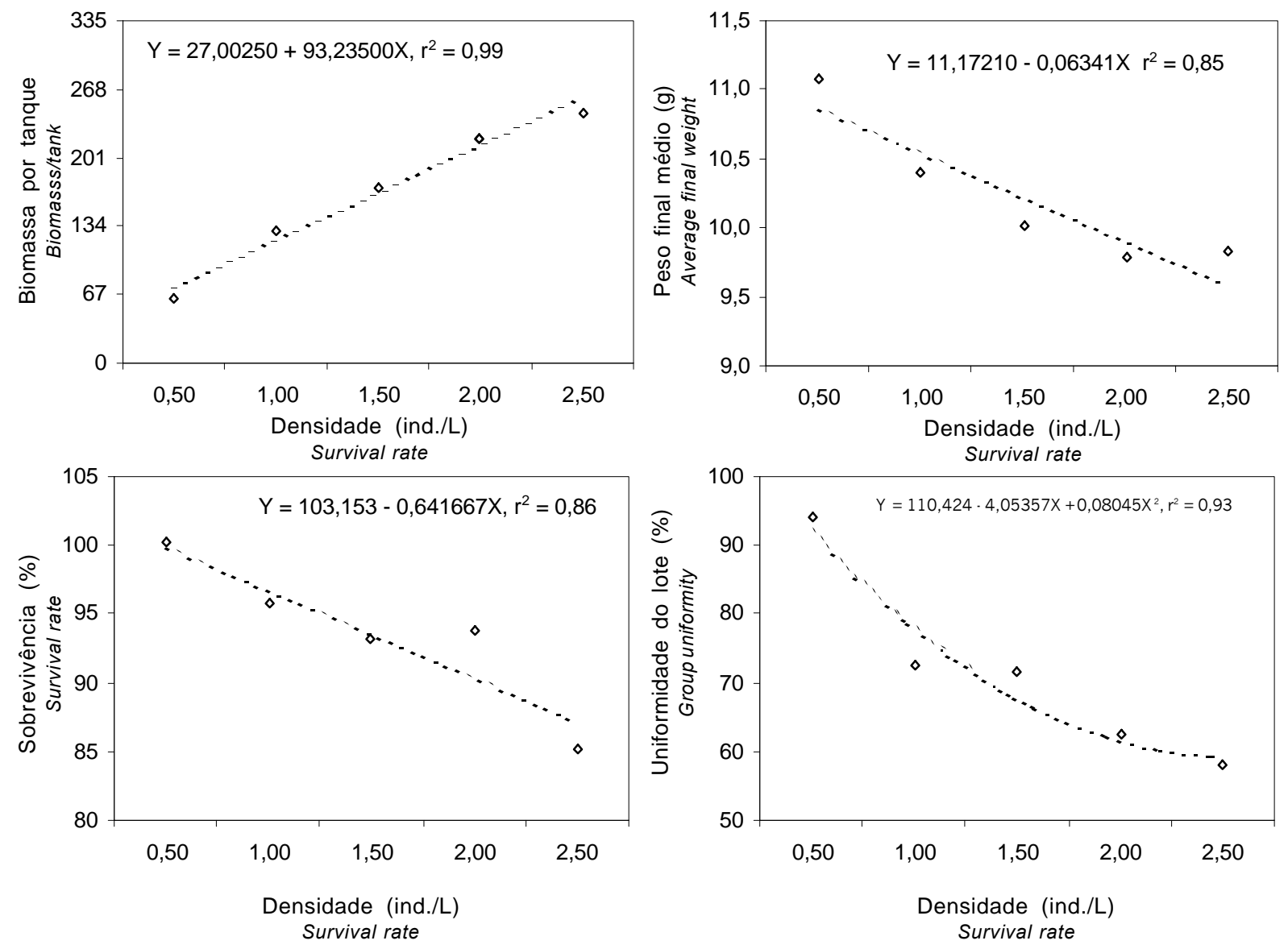

Figura 1 - Biomassa por tanque, peso final médio, taxa de sobrevivência e uniformidade do lote de girinos de rã-touro (Rana catesbeiana), em função das diferentes densidades de estocagem.

Figure 1 - Biomass by net tank, final mean weight, survival rate and group uniformity of bullfrog (Rana catesbeiana) tadpoles, according to different stocking density. 
competição por espaço e hierarquia, conforme relatado por Dash \& Hota (1980), os quais observaram que, em altas populações de girinos de Rana tigrina, a taxa de crescimento é menor, devido à competição por alimento, o mesmo foi observado por Browne et al. (2002) com girinos de Litoria aurea. Outros fatores apontados como determinantes são qualidade de água do cultivo e produção do fator inibidor de crescimento (Browne et al., 2002), entretanto, como os animais estavam em tanques rede, os parâmetros de qualidade de água e concentração do fator inibidor de crescimento deveriam ser os mesmos nas unidades experimentais, ficando, desta forma, os fatores relacionados à biologia de espécie, como a competição, hierarquia como os mais determinantes nas reduções destes parâmetros de desempenho produtivo.

\section{Conclusões}

Em menores densidades, obtêm-se girinos maiores e lotes mais uniformes com melhor taxa de sobrevivência, entretanto, pode-se utilizar a densidade de estocagem de até $2,50 \mathrm{ind} / \mathrm{L}$ em tanque-rede para girinos de rã-touro (Rana catesbeiana), dependendo das instalações disponíveis e interesse do produtor, uma vez que a taxa de sobrevivência obtida nesta densidade ainda é satisfatória.

\section{Literatura Citada}

ADAMS, I.K.; BRUINSMA, E.C. Intensive commercial bullfrog culture: a Brazilian experience. Aquaculture Management, v.358, n.4, p.28-44, 1987.

ALBINATI, R.C.B.; LIMA, S.L.; TAFURI, M.L. et al. Digestibilidade aparente de dois alimentos protéicos e três energéticos para girinos de rã touro (Rana catesbeiana, Shaw, 1802). Revista Brasileira de Zootecnia, v.29, n.6, p.2151-2156, 2000.

ALBINATI, R.C.B.; COSTA, G.B.; NEVES, A.P. et al. Efeito da densidade populacional de girinos de (Rana catesbeiana Shaw, 1802) sobre o tempo de metamorfose e peso dos imagos. Arquivos da Escola de Medicina Veterinária da UFBA, v.19, n.7, p.75-86, 1998.

BROWNE, R.K.; POMERING, M.; HAMER, A.J. High density effects on the growth, development and survival of Litoria aurea tadpoles. Aquaculture, v.215, p.109-121, 2003.

CARMONA-OSALDE, C.; OLVERA-NOVOA, M.A.; RODRÍGUEZ-SERNA, M. et al. Estimation of protein requirement for bullfrog (Rana catesbeiana), tadpoles and its effects on metamorphosis ratio. Aquaculture Research, v.141, p.223-231, 1996.

CASTRO, J.C.; LIMA, S.L.; DONZELE, J.L. et al. Energia metabolizável de alguns alimentos usados em rações de rãs. Revista Brasileira de Zootecnia, v.27, n.6, p.1051-1056, 1998. CASTRO, J.C.; PINTO, A.T. Qualidade de água em tanques de girinos de rã-touro, Rana catesbeiana, Shaw, 1802, cultivadas em diferentes densidades de estocagem. Revista Brasileira de Zootecnia, v.29, n.6, p.1903-1911, 2000.

DAMBO,W.B.; RANA, K.J. Effect of density on growth and survival of Oreochromis niloticus (L.) fry in the hatchery. Aquaculture and Fisheries Management, v.23, n.1, p.71-80, 1992.

DASH, M.C.; HOTA, A.K. Density effects on the survival growth rate, and metamorphosis of Rana tigrina tadpoles. Ecology, v.61, n.5, p. 1025-1028, 1980.

EGNA, H.S.; BOYD, C.E. Dynamics of pond aquaculture. Boca Raton: CRC Press, 1997. 342p.

EUCLYDES, R.F. Manual de utilização do programa SAEG Viçosa, MG: Unviersidade Federal de Viçosa, 1983. 59p.

FIGUEIREDO, M.R.C.; AGOSTINHO, C.A.; BAÊTA, F.C. et al. Efeito da temperatura sobre o desempenho da rã-touro (Rana catesbeiana, Shaw, 1802). Revista Brasileira de Zootecnia, v.28, n.4, p.661-667, 1999.

FONTES, N.A.; SENHORINI, J.A.; LUCAS, A.F.B. Efeito de duas densidades de estocagem no desempenho larval do paqui, Piaractus mesopotamicus (fêmea) (Holmberg, 1887) X Colossoma macropomum (macho) (Cuvier, 1818) em viveiros. Boletim Técnico do CEPTA, v.3, n.único, p.23-32, 1990.

FURUYA, W.M.; SOUZA, S.R.; FURUYA, V.R.B. et al. Dietas peletizada e extrusada para machos revertidos de tilápia do Nilo (Oreochromis niloticus) na fase de terminação. Ciência Rural, v.28, n.3, p.483-487, 1998.

GILLESPIE, G.R. Impacts of sediment loads, tadpole density, and food type on the growth and development of tadpoles of the spotted tree frog Litoria spenceri : a in-stream experiment. Biologic Conservation, v.106, n.1, p.141-150, 2002.

HAYASHI, C.; SOARES, C.M.; FERNANDES, C.E.B. et al. Efeito da densidade populacional no desenvolvimento de girinos de perereca (Scynax fuscovaria) In: CONGRESSO BRASILEIRO DE AQUICULTURA, 12., 2002, Recife. Anais... Recife: ABRAq, 2002. p.203.

JUSTO, C.L.; PENTEADO, L.A.; FONTANELLO, D. et al. Ganho de peso de girinos de Rana catesbeiana Shaw, 1802, em criação intensiva, sob diferentes densidades populacionais. Boletim do Instituo de Pesca, v.12, n.3, p.31-37, 1985.

KHAN, M.S. Effect of population density on the growth, feed and protein conversion efficiency and biochemical composition of a tropical freshwater catfish, Mystus nemurus (Curvier \& Valenciennes). Aquaculture and Fisheries Management, v.25, p.753-760, 1994.

LIMA, S.L.; COSTA, C.L.S.; AGOSTINHO, C.A. et al. Estimativa do tamanho da primeira maturação sexual da rãtouro, Rana catesbeiana, no sistema anfigranja de criação intensiva. Revista Brasileira de Zootecnia, v.27, n.3, p.416-420, 1998.

MARTINÉZ, I.P.; ÁLVARES, R.; HERRAÉZ, M.P. Growth and metamorphosis of Rana pirezi larvae in culture: effects of larval density. Aquaculture, v.142, n.1, p.163-170, 1996.

NEWMAN, R.A. Ecological constraints on amphibian metamorphosis: Interactions of temperature and larval density with responses to changing food level. Oecologia, v.115, n.1/2. p.9-16, 1998.

RODRÍGUEZ-SERNA, M.; FLORES-NAVA, A.; OLVERANOVOA, M.A. et al. Growth and production of bullfrog Rana catesbeiana Shaw, 1802, at three stocking densities in a vertical intensive culture system. Aquaculture Engineering, v.15, n.4, p.233-242, 1996. 
SEIXAS FILHO, J.T.; MELO, S.C.R.P.; SILVA, J.M.F. et al. Efeito de níveis de energia e proteína bruta no desempenho de girinos (Rana catesbeiana, Shaw, 1802). Revista Brasileira de Zootecnia, v.27, n.4, p.664-669, 1998.

SOARES, C.M.; HAYASHI, C.; GALDIOLI, E.M. et al. Utilização de diferentes níveis protéicos em rações para girinos de rã-touro (Rana catesbeiana, Shaw, 1802). In: CONGRESSO BRASILEIRO DE ENGENHARIA DE PESCA, 12., 2001, Foz do Iguaçu. Anais... Foz do Iguaçu: AEP-SUL e FAEP-BR, 2001. (CD-ROM)
SOARES, H.A.; FONTANELLO, D.; REIS, J.M. et al. Efeito da densidade de população no ganho de peso de girinos da rãtouro (Rana catesbeiana Shaw, 1802). Boletim do Instituto de Pesca, v.10, n.único, p.47-51, 1983.

VIZOTTO, L.D. Ranicultura. Ciência e Cultura, v.36, n.1, p.42-45, 1984.

Recebido em: 22/08/02

Aceito em: 23/06/03 